
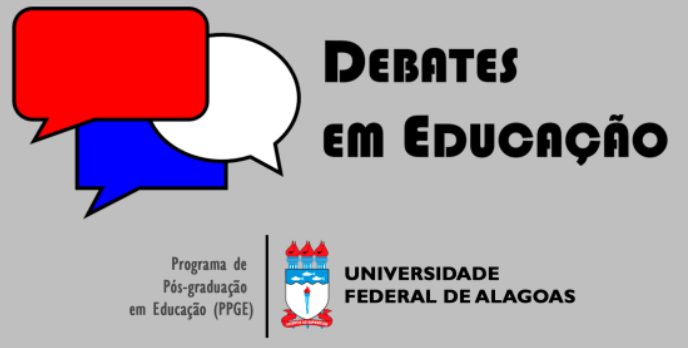

ISSN Eletrônico 2175-6600

Vol. 12 | Número Especial | 2020

Maria Christine Berdusco Menezes

(9) iD

Universidade Estadual de Maringá (UEM) mcbmenezes@uem.br

Rosângela Célia Faustino

9 iD

Universidade Estadual de Maringá (UEM) rcfaustino@uem.br

Maria Simone Jacomini Novak 9

Universidade Estadual do Paraná (UNESPAR) maria.novak@unespar.edu.br

\section{O ENSINO DA LEITURA E ESCRITA EM UMA ESCOLA INDÍGENA KAINGANG: CONTRIBUIÇÕES AO BILINGUISMO}

\section{RESUMO}

Entre os Kaingang no Paraná a escrita em língua portuguesa tem sido usada, reivindicada e aprendida desde o aldeamento, no início do século $X X$. Neste texto, por meio de pesquisa bibliográfica e empírica, abordamos o ensino da leitura e escrita em uma comunidade Kaingang no Vale do Ivaí, Paraná. Destacamos elementos da vivência das crianças e algumas formas próprias de aprender com autonomia nos grupos familiares. Analisamos como a escola organiza o ensino a partir da decisão da comunidade pela alfabetização em língua portuguesa. Os resultados evidenciam a necessidade de fortalecimento do bilinguismo e da escrita em língua Kaingang por meio da formação de professores indígenas e da produção de materiais didático diversificados.

Palavras-chave: Indígenas Kaingang. Leitura e Escrita. Bilinguismo.

\section{TEACHING READING AND WRITING IN A KAINGANG INDIGENOUS SCHOOL: CONTRIBUTIONS OF BILINGUALISM}

\section{ABSTRACT}

Among the Kaingang in Paraná, writing in the Portuguese language has been used, claimed and learned since the creation of the indigenous reserves, in the beginning of the 20th century. In this text, through bibliographic and empirical research, we approach the teaching of reading and writing in a Kaingang community in Vale do Ivaí, Paraná. We highlight elements of the children's experience and some specific ways of learning independently in family groups. We analyzed how the school organizes teaching based on the community's decision to become literate in Portuguese. The results show the need to strengthen bilingualism and Kaingang writing through the training of indigenous teachers and the production of diverse teaching materials.

Keywords: Kaingang Indigenous. Reading and Writing. Bilingualism.

Submetido em: 15/04/2020

Aceito em: 01/06/2020

Publicado em: 10/12/2020

do http://dx.doi.org/10.28998/2 I75-6600.2020v I 2nEspp275-296 


\section{INTRODUÇÃO}

O ensino da leitura e da escrita é um tema recorrente na área da educação, dada sua complexidade e as implicações para as demais etapas de escolarização. Em sociedades indígenas, a abordagem do tema é feita de forma interdisciplinar pois requer conhecimentos históricos, linguísticos, pedagógicos e culturais. A Constituição de 1988, ao definir, no Artigo 210 , que os povos indígenas têm direito à utilização de suas línguas maternas no ensino fundamental, bem como a processos próprios de aprendizagem (BRASIL, 1988), lança a obrigatoriedade de implementação do direito ao ensino bilíngue.

Este texto visa discutir o tema buscando analisar a prática docente no Colégio da Terra Indígena Ivaí, situada no Vale do Ivaí, Paraná. Nessa comunidade, habitam I.699 (um mil seiscentos e noventa e nove) indígenas (IBGE, 20I2) e todos são falantes da língua kaingang. As crianças ingressam na escola, na educação infantil (ANDRIOLI, 20/9), por volta dos 4/5 anos, com a presença de professores indígenas. No entanto, por decisão da comunidade, quando iniciam o primeiro ano do ensino fundamental, a leitura e a escrita são ensinadas em língua portuguesa, por professores não indígenas, mas com a presença de professores indígenas na sala de aula, que atuam como tradutores da língua portuguesa e auxiliam na condução das atividades (MENEZES, 20 I6).

Para discutir o tema faz-se necessária a análise de questões históricas e culturais que vão desde as necessidades geradas a partir da ocupação dos territórios Kaingang da região (MOTA, 1994), até a forma como estas comunidades tiveram contato com a escola e como esta instituição é organizada, a partir da Constituição de 1988 e legislação subsequente, que garantiu aos povos indígenas uma educação escolar específica, diferenciada, intercultural e bilíngue (FAUSTINO, 2006).

Este texto é resultado de estudos teóricos e pesquisas de campo realizadas junto ao Programa de Pós-Graduação em Educação (PPE) e Laboratório de Arqueologia, Etnologia e Etno-História da Universidade Estadual de Maringá (LAEE/UEM). Realizou-se no âmbito do Observatório da Educação Escolar Indígena (OBEDUCNEM) e do Programa Saberes Indígenas na Escola, Núcleo UEM (SIE-UEM), com autorização da comunidade, da equipe escolar gestora, da Fundação Nacional do Índio (FUNAI) e do comitê de ética na pesquisa do CNPq ${ }^{1}$.

Trata-se de um recorte das observações realizadas no Colégio da Terra Indígena Ivaí, no período de 2014 a 2017. A pesquisa de campo ocorreu na comunidade e na escola onde foram feitos diálogos com professores e equipe pedagógica, observação de atividades em sala de aula, com registro em caderno de campo e fotográficos.

\footnotetext{
I Parecer no 573.633 de 27/0I/2014 - COPEP e Autorização nº 42 AAEP/PRES/2015 - FUNAI.
} 
De acordo com Mota (1994) e Tommasino (1995), os Kaingang possuem uma longa história de existência e resistência no Paraná, com uma complexa organização sociocultural, cujas bases se sustentam na oralidade. A cultura Kaingang, registrada por diferentes etnólogos (MABILDE, I983; BORBA, 1908), e pesquisadores atuais, é repleta de simbologias como a pintura corporal, os grafismos, os traçados do artesanato (SILVA, 200 I), (CLAUDINO, 20I I), a alimentação tradicional, o uso de remédios do mato, os rituais de cura, de proteção, de tratamento com os mortos e outros. Com base nessa organização enfrentaram as situações de contato e aldeamento, passando, a partir disso, a ter necessidade de aprender a língua portuguesa, oral e escrita, necessária para a compreensão e negociações com o Estado brasileiro e o poder público de forma geral.

Mota (1994) sistematizou as inúmeras estratégias políticas deste povo no Paraná, após o aldeamento, definidas e colocadas em prática por meio da organização em grupos familiares extensos. Podemos inferir, com base no autor, que a comunicação entre os Kaingang é diversificada e bastante complexa e que, a escrita alfabética foi sendo incorporada pelas comunidades no processo de ocupação dos territórios indígenas, principalmente na política de aldeamento, desde o final do século XIX e início do século XX. Esta política alterou radicalmente a vida e a relação dos Kaingang com a sociedade envolvente, levando-os a terem necessidade de domínio do código escrito como uma de suas estratégias de sobrevivência. Nos aldeamentos, escolas estavam sendo criadas e impostas como uma das formas de "civilizar" e diminuir as resistências indígenas. Mas, há que se refletir sobre o papel que os Kaingang exerceram em relação a esta imposição.

Mota (1994) demonstra que no período, os Kaingang no Paraná, procuravam manter entre os grupos de lideranças, indígenas que sabiam ler e escrever, pois estavam reposicionando suas estratégias em meio a perseguições, disputas de terras, reconfiguração de mapas territoriais, notícias, leis, acordos e tratados com o governo.

Para analisar a escrita e as práticas docentes com comunidades Kaingang, na atualidade, faz-se necessário, também, conhecer aspectos linguísticos e socioculturais de cada Terra Indígena, bem como os sujeitos envolvidos no processo, que interagem com a escola de diferentes formas. É necessário reconhecer aspectos culturais e como a aprendizagem escolar, a partir do trabalho de professores indígenas e não indígenas, tem ocorrido e em que medida estão sendo considerados os processos próprios de aprendizagem, como determina a legislação atual (FAUSTINO, 2006; MENEZES, 20 I6).

Para esta discussão o artigo está organizado em subtítulos que abordam a criança Kaingang e seus processos próprios de aprendizagem; a situação sociolinguística da comunidade indígena; o trabalho de professores indígenas e não indígenas que atuam nos anos iniciais do ensino fundamental; a organização da escola indígena; e o ensino da leitura e escrita em uma escola indígena, a maior escola Kaingang do 
Paraná, situada em uma comunidade onde todos são falantes da língua kaingang e usam esta língua em todas as relações internas da comunidade.

\section{A CRIANÇA KAINGANG E OS PROCESSOS PRÓPRIOS DE APRENDIZAGEM}

Segundo Faustino e Mota (2016), o entendimento da criança indígena pressupõe estudos sobre a cultura, a história e a etnologia indígena. Os autores afirmam serem poucos os registros sobre a criança Kaingang e apontam alguns relatos de observações feitas por etnógrafos que estiveram junto aos Kaingang entre os séculos XIX e XX sendo, os principais, o engenheiro Pierre François Alphonse Mabilde; o administrador de colônias indígenas Telêmaco Borba; e o agente do Serviço de Proteção ao Índio (SPI), Luiz Bueno Horta Barboza. Mabilde (1983) registrou observações feitas em relação à gravidez, ao parto, ao momento de dar nome à criança e o papel das mulheres Kaingang no grupo familiar. Borba (1908) e Horta Barboza (19/3) relataram o papel da família na educação dos filhos, a participação do homem de forma atenciosa e cuidadosa com a mulher e o afeto de ambos em relação aos filhos (FAUSTINO; MOTA, 2016).

Na pesquisa em Terra Indígena Ivaí/Paraná, destacamos nossa observação em relação à autonomia da criança, mesmo com a presença da mãe e familiares, junto a ela, permanentemente. Esta presença dos adultos há que ser refletida, pois, mesmo os pais, irmãos e primos estando muito próximos, raramente a criança é ajudada em atividades que pode fazer sozinha. Por exemplo, quando tenta calçar um chinelo, mesmo sendo muito pequena, os pais a observam, com paciência e discrição, até que ela consiga, à maneira dela, colocar os chinelos. Nesse processo consideram seu ritmo e forma própria de fazer as coisas dando-Ihes, assim, oportunidade de aprender com a prática. Com este tratamento, acreditam que a criança será forte. Em uma linguagem escolar diríamos que os Kaingang, com práticas como esta, promovem em suas crianças um grande desenvolvimento psicomotor que as fortalece física e intelectualmente.

Coroaia (2013, p. 59), apresentou alguns cuidados das mulheres Kaingang desde a gestação, o parto e o pós-parto. Segundo a autora, embora "[...] a descendência seja patrilinear, são as mulheres que decidem quando engravidar, pois a gestação, o parto, a amamentação e o cuidado com as crianças é papel central da mulher." Essa questão é importante para a compreensão da educação da criança, pois esta passará grande parte de seu tempo muito próxima e sob cuidados da mãe, das tias, irmãs, primas e permanecerá, quando jovem, se for menina, no grupo das mulheres.

Silva (201 I, p. 17), observou que para conhecer o cotidiano da criança na aldeia, é preciso acompanhar as mulheres, pois são elas as responsáveis pelos cuidados com os pequenos. De acordo com 
a autora, que vivenciou um período na Aldeia Icatu-SP, as duas mulheres que acompanhou sempre diziam: "[...] você precisa deixar de ir atrás da meninada. Falar de criança é aqui mesmo com a gente, porque a gente que sabe de criança, sabe de criança quem tem criança" (grifos da autora).

Garlet (20।0), abordou a criança Kaingang em contexto urbano, quando esta sai da aldeia junto com sua família para a venda do artesanato. Destacou questões sociais e os desdobramentos do convívio familiar indígena em áreas urbanas, que muitas vezes se manifestam na forma de discriminação, por desconhecimento das questões culturais indígenas. A redução de seus territórios e a dificuldade de sustentabilidade faz com que as famílias migrem, em períodos específicos, para as cidades, principalmente para vender artesanato, onde vivenciam situações de vulnerabilidade, preconceito e exclusão social.

Segundo Ferreira (20|4), Faustino e Mota (20|6), as crianças são formadas para terem autonomia e isso faz com que elas tenham muita liberdade em todas as atividades que são realizadas junto com os adultos. Até por volta dos três anos de idade ficam muito perto da mãe, tias e avós, em muitas comunidades permanecem penduradas em suas $\operatorname{costas}^{2}$ (BORBA, 1908), aquecidas, cuidadas muito de perto, e, posteriormente, por volta dos quatro, cinco anos, começam a sair pela aldeia em companhia dos irmãos e primos, para brincar em lugares delimitados pela família.

Pinheiro (20 I 5), professor Kaingang, define fases na infância desta etnia, assim nominadas: GIR SI: bebê - do nascimento ao primeiro ano; GiR: criança - de I a 13 anos; TI: fase adulta - de 13 a 60 anos; KÓFA: velhice - a partir dos 60 anos ou quando se torna avô(ó). As atividades na fase GiRR, que envolve a socialização primária, ocorrem por meio de muitas ações como o brincar livremente nos rios (mesmo naqueles que estão muito sujos e poluídos), ou quando as mães lavam roupas. Aprendem, assim, umas com as outras, em vivências coletivas. Estão sempre muito atentas ao ambiente e ao que está ocorrendo ao seu redor.

Por cuidá-los e tê-los sempre por perto para que vivenciem e aprendam atividades da família, mães Kaingang, ao viajar para vender artesanato nas cidades, não deixam os filhos pequenos na aldeia. Elas sabem que as crianças estão em constante aprendizado, o que possibilita o seu desenvolvimento (ANDRIOLI; FAUSTINO, 2019). Os/as Kaingang acreditam que a sobrevivência da criança depende da liberdade e das aprendizagens dos conhecimentos e experiências repassados pelos mais velhos (pais, tios, avós) e aprendidas na prática. Os cuidados das crianças, sua saúde, andanças e novos aprendizados são parte importante das suas vivências familiares (FERREIRA, 20I4).

Andrioli (2019, p. 22), buscou "[...] compreender as políticas educacionais para a educação infantil indígena, aspectos da cultura, sustentabilidade e educação tradicional de indígenas Kaingang da região do Vale do Ivaí". Destacou que a criança acompanha sempre a família nos espaços urbanos, pois assim ela

\footnotetext{
${ }^{2}$ Borba (1908, p. 12) observou que "[...] as mães andam sempre com os filhos novos às costas, embrulhadas em curús e com uma faixa larga de imbira passada pela cabeça para os suportar; amamentam-os por dous a quatro anos geralmente até terem outro."
} 
permanece inserida, vivenciando elementos socioculturais e desenvolvendo seus processos próprios de aprendizagem. Em suas observações, no período em que esteve com uma família extensa, em um centro urbano, Andrioli (2019) observou que as crianças são muito respeitadas. Não há nas relações familiares a alteração de voz dos adultos, ordens ou imposição de afazeres. Prevalecem formas de comunicação baseada em gestos, olhares e diálogos curtos - apenas em língua kaingang - embora adultos desta comunidade falem a língua portuguesa. As crianças Kaingang, mesmo nas cidades, em ruas e avenidas movimentadas, têm liberdade e autonomia para brincar, para comercializar artesanato, para receber e manusear doações junto com a família, e, embora possa não parecer, aos olhos de algumas pessoas das cidades, as famílias estão sempre atentas e cuidando dos filhos/as, em conformidade com as suas tradições.

O pesquisador Kaingang, Bruno Ferreira (2014, p. 8), explicou aspectos da educação Kaingang discutindo "[...] as formas de construir conhecimentos e sua transmissão para as crianças" afirmando que "crianças e adultos ocupam os mesmos espaços para aprender". Isso permite compreender que o ensino e a aprendizagem ocorrem, concomitantemente, no grupo familiar, por meio da socialização, um dos aspectos que o autor elenca como muito importante para a educação desta etnia. Tomemos o exemplo da organização do trabalho na produção do artesanato.

\footnotetext{
Uma mãe Kaingang, ao chegar no lugar onde tem taquaras - pode ser taquara mansa ou taquaruçu - ou cipós, começa a colher as taquaras. Ai fica muito claro que cada um dos filhos tem uma função a desempenhar: os filhos mais velhos ou ainda poderíamos dizer os maiores, tomam a iniciativa de ajudá-la a cortar o material. Os filhos mais novos ou menores fazem outra parte do serviço: organizar os montes de taquara ou cipó que serão carregados pelos maiores ou mais velhos (FERREIRA, 2014, p.68).
}

Essa atividade de busca da taquara faz parte dos conhecimentos tradicionais/ancestrais Kaingang e não há necessidade de que a mãe verbalize para os filhos quais são suas funções junto ao grupo familiar. Esta atitude é "internalizada" (VIGOTSKI, 2007) e já está "apropriada" pelas crianças de acordo com suas vivências familiares e com o que observam de forma contínua em sua sociabilidade. Os pais promovem a criança "[...] experimentar e ter a possibilidade da execução e assim exercer suas habilidades" em conformidade com o ritmo e a idade (FERREIRA, 20।4, p. 67).

Na confecção do artesanato, as mulheres, geralmente sentadas no chão, fazem os trançados, produzem balaios e cestos com diversos formatos e grafismos, conforme tradições familiares e, também, incorporando elementos novos, que acham bonitos. Em uma de nossas observações perguntamos sobre um grafismo diferente e a mulher nos disse que "copiou" o desenho de um "papel de bala".

No fazer da cestaria, bebês e crianças pequenas ficam juntas de suas mães. Se a criança mama no peito, estando a mãe sentada ao chão, fica próxima e acessível para que a ela mame quando quiser (FAUSTINO, 2006), ao mesmo tempo que vivencia, brinca em meio às atividades do grupo de mulheres da família e aprende. 
Há momentos (planejados conforme as épocas do ano e a disponibilidade de transporte) em que as mulheres Kaingang saem de suas aldeias e se dirigem às cidades para vender artesanato. Estando na cidade, conforme Andrioli e Faustino (2019), permanecem com a organização familiar, ou seja, mães, tias e irmãos mais velhos cuidando das crianças e, um homem jovem ou adulto, cuidando de todos, a uma certa distância que the permita uma ampla visão do grupo e das crianças que se movimentam.

Os conhecimentos que as crianças Kaingang possuem e suas diferentes formas de aprender são semelhantes aos comportamentos de outros grupos indígenas. Paradise, pesquisadora do DIECINVESTAV/México registra que os indígenas Mazahua possuem um estilo de interação "separado-masjunto" em diferentes situações do dia a dia. Ela observa que essa interação ocorre nos diferentes sistemas de comunicação, ensino e aprendizagem indígena, por meio da linguagem não verbal.

A autora usa a expressão "separado-mas-junto" para ilustrar situações em que os bebês e crianças estão com a mãe ou um parente, mas "não requerem e nem lhes é dada a atenção" (PARADISE, 20 I 2). Mesmo em situações que requerem ação da mãe, por exemplo a troca de roupa, não ocorre com troca direta de olhares. A atenção fica na situação em si e não na criança. A criança, por sua vez, enquanto está sendo trocada pela mãe, está observando os movimentos e acontecimentos ao seu redor. Essa ausência de comunicação visual e oral direta, não significa descaso físico ou emocional com a criança, são formas de interação diferenciadas. Paradise (20।2, p. I 8) explica que "[...] as mulheres não se distanciam das crianças e seu calor e afeição maternos são evidentes". Estar "separado-mas-junto" "permite o cuidado com as crianças em modos que minimizam a interferência e o constrangimento". Na educação familiar se desenvolve "[...] autoconfiança, responsabilidade, respeito, atitudes apropriadas e os meios de cooperação e coordenação de atividades, definidos pela interação social” (PARADISE, 20 I2, p. 21).

Entre os Kaingang, na organização sociocultural por grupos familiares, o indivíduo tem autonomia mas nunca está só. $\bigcirc$ trabalho, os passeios, as festas, as viagens, tudo ocorre no âmbito da organização familiar. Na interação, as crianças aprendem pela vivência, por meio da observação, da imitação às atividades desenvolvidas pela família, e, assim, adquirem conhecimentos e atitude de participação.

\section{SITUAÇÃO SOCIOLINGUÍSTICA DA COMUNIDADE KAINGANG DO VALE DO IVAí}

Pensando estas formas próprias de aprender dos Kaingang e, ao mesmo tempo, sua procura e interesse pela leitura e escrita (FAUSTINO, 2006), propor metodologias coerentes para o ensino da leitura e escrita, em um contexto indígena, requer como primeiro passo, em consonância com Amaral (20l I), o conhecimento da realidade sociocultural e da situação linguística da comunidade e das crianças. No caso da Terra Indígena Ivaí, situada no Vale do Ivaí, as crianças falam apenas em kaingang e quando iniciam o 
ensino fundamental, a língua ensinada em sua forma oral e escrita é a língua portuguesa. Há, no entanto, em consonância com a nova legislação, a presença permanente de professores indígenas como regentes - em língua indígena - ou como auxiliares de sala, em classes de alfabetização.

O último recenseamento (IBGE, 2010) demonstrou existirem 896,9 mil indígenas, 305 etnias e 274 línguas indígenas diferentes nas diversas regiões do Brasil. Os Kaingang representam um dos grupos étnicos que tem o maior número de falantes em língua indígena no Brasil e está territorializado na Região Sul, nos estados de Santa Catarina, Rio Grande do Sul e Paraná e na Região Sudeste no estado de São Paulo, totalizando, 37.470 indígenas.

Um levantamento feito pelo governo do estado, para o desenvolvimento do Projeto Multissetorial do Paraná - Estratégia de Participação dos Povos Indígenas (EPPI), em parceria com o Banco Mundial, estimou uma população de I I .678 indígenas Kaingang, vivendo em I 6 Terras Indígenas, sendo que destas, 12 estavam regularizadas e quatro em processo de reconhecimento (PARANÁ, 20 |6).

A língua kaingang, conforme define Rodrigues (2012), pertence à família Jê do tronco Macro-jê. A linguista Kaingang Marcia Nascimento (2013, p. 7), afirma que "Em termos de vitalidade linguística, em nossa avaliação, é bem possível que o kaingang seja falado por cerca de 60\% da população atual, ou seja, pelo menos 18 mil dos 30 mil Kaingang seriam falantes da língua”. Segundo a pesquisadora indígena, [...] há comunidades onde a língua está muito viva, sendo adquirida pelas crianças como língua materna e outras em que se encontra seriamente ameaçada, pois a transmissão intergeracional já está seriamente comprometida (NASCIMENTO, 2013, p. 7).

No caso da Terra Indígena Ivaí, todos são falantes da língua kaingang como primeira língua e dela tem um profundo conhecimento oral (FAUSTINO, 2006). A pesquisa de campo evidenciou que as crianças se comunicam com a família somente em língua kaingang. Apesar de irem frequentemente para as cidades com seus familiares, começam a se inserir e ter mais contato com a língua portuguesa escrita e oral (brincadeiras com alfabetos móveis, visualização de cartazes nas paredes, músicas infantis educativas...), quando vão à escola, desde a educação infantil.

Quando mais velhos, por volta de oito e nove anos, entendem um pouco a língua portuguesa, mas dela fazem pouquíssimo uso, ainda que tenham contato intenso com televisão, programas de rádio, bailes, celebrações de igrejas cristãs na aldeia, campeonatos de futebol nas cidades, que participam com seus familiares, dentre outras experiências com a língua portuguesa. Mesmo na escola falam entre si, o tempo todo, em língua kaingang. Com os professores não índios falam o básico em português: respondem cumprimentos, fazem algum pedido muito direto. Em sala de aula, toda a interação oral entre colegas e parentes, se dá em língua kaingang, mesmo em aulas de professores não-indígenas.

Ensinar a língua portuguesa, em sua forma oral e escrita às crianças Kaingang, desde o primeiro ano do ensino fundamental, é decisão da comunidade em relação à organização da escola (MENEZES, 20 I6). 
Aliás este é um dos principais motivos pelos quais esta comunidade envia seus filhos com regularidade à escola: para aprender "bem" a língua portuguesa. Em registros de diálogos de campo realizados no âmbito do projeto OBEDUCNEM e SIE-UEM, no período de 2014 a 2017, os mais velhos, as mães e as lideranças afirmam que as crianças necessitam aprender a língua portuguesa para não sofrer os preconceitos que eles enfrentaram e para conseguir empregos/renda, pois a terra indígena não tem mais propiciado o sustento de todos.

Com base em pesquisa de Mota (1994, p. 203), que mostra que "[...] em 1935, Herbert Baldus estuda os Kaingang de Palmas, no sul do Estado, e [...] reproduz uma carta de chefes Kaingang à comissão de proteção ao índio"; evidencia-se que o interesse e a necessidade de aprender a ler e escrever, conforme já afirmado, remonta ao início do século $X X$ quando se intensificam as relações desse povo com a sociedade envolvente.

Na escola da Terra Indígena Ivaí, o ensino da leitura e escrita inicia-se pela língua portuguesa, quando a criança tem por volta de seis/sete anos de idade. As crianças aprendem, de forma concomitantemente, o português na oralidade e na escrita. Este é o modelo de bilinguismo que a comunidade defende e adotou como sendo a melhor forma de as crianças Kaingang aprenderem na escola.

No decorrer do ensino fundamental e até o ensino médio, crianças e jovens Kaingang desta comunidade leem textos didáticos, copiam do quadro, assistem filmes e realizam atividades escolares em língua portuguesa. A partir do terceiro ano do ensino fundamental, insere-se, também o ensino sistemático da língua kaingang em sua forma escrita (MENEZES, 20I6). Nessa metodologia, crianças e jovens, tem contato com as duas línguas, predominando na escrita e leitura, o uso da língua portuguesa. Destaca-se, ser bastante complexo o ensino e a aprendizagem da língua kaingang escrita, haja vista a ausência de gramáticas nesta língua, as diferenças entre os alfabetos, a existência de diferentes dialetos, a ausência de materiais didáticos apropriados, currículos específicos e orientações pedagógicas em kaingang, bem como a insuficiente formação acadêmica dos professores indígenas.

É recomendado pela legislação, como a Portaria Interministerial n ․ 559/I99। (BRASIL, I99|), o Referencial Curricular Nacional para as Escolas Indígenas (BRASIL, 1998), o Parecer I4/99 (BRASIL, I999), os Referenciais para a Formação de Professores Indígenas (BRASIL, 200 I), a Resolução n 5/20 I 2 (BRASIL, 20 I2) e a Resolução n I/20 I 5 (BRASIL, 20 I 5) que os professores das escolas indígenas, sejam indígenas, mas essa realidade não se concretizou em todas as escolas no Paraná, mesmo transcorridos mais de 30 anos da Constituição Federal de 1988 que oficializou o ensino bilíngue no país.

No Paraná é muito discrepante a presença de professores indígenas nas escolas indígenas. Isto se dá, em grande parte, pela ausência de formação acadêmica, mesmo com uma importante política estadual de inclusão nas universidades públicas (NOVAK, 20I4; FAUSTINO; NOVAK; RODRIGUES, 2020). As 
escolas possuem, majoritariamente, a presença de professores não indígenas que não falam as línguas indígenas e pouco tem acesso à formação pedagógica em relação às culturas indígenas .

Ao todo, nas 39 escolas indígenas existentes no estado, atuam 764 professores em sala de aula, desses, 325 são indígenas e 439 não indígenas (PARANÁ, 2020a). Conforme levantamentos realizados na Ação Saberes Indígenas na Escola, (SIE-UEM/20I9), entre os 325 professores indígenas, cerca de 60 tem formação superior, atuando em sala de aula e nas equipes pedagógicas. Somada à insuficiência da formação superior de professores indígenas no Paraná há ainda o fato de serem contratos por tempo determinado, em processos de seleção simplificada (PSS) o que causa uma grande rotatividade docente nas escolas indígenas.

Para que ocorra a aprendizagem da leitura e escrita em contexto bilíngue kaingang, valorizando-se os conhecimentos prévios linguísticos e culturais da criança, entendemos ser fundamental que os professores sejam indígenas, tenham formação acadêmica (ensino superior), conhecimentos culturais e linguísticos e experiência docente que thes possibilitem construir/desenvolver pedagogias próprias.

Na escola da Terra Indígena Ivai, trabalham, atualmente, 89 professores. No ano de 2020 o número de professores indígenas, conforme pode ser observado na tabela abaixo, pela primeira vez desde que a escola existe (FAUSTINO 2006) tornou-se maior do que o número de professores não-indígenas, porém não houve ampliação da formação inicial e continuada.

São ofertadas na escola, turmas de Educação Infantil, Anos Iniciais e Finais do Ensino Fundamental, Ensino Médio, Sala de Recursos e Atividades Complementares ${ }^{3}$ :

Tabela I: Colégio Estadual Indígena Cacique Gregório Kaekchot

\begin{tabular}{cc}
\hline \multicolumn{2}{c}{ Professores } \\
\hline Indígenas & 45 \\
\hline Não Indígenas & 44 \\
\hline Total de professores & 89 \\
\hline Matrículas & \\
\hline Educação Infantil & 113 \\
\hline Anos Iniciais do Ensino Fundamental & 302 \\
\hline Anos Finais do Ensino Fundamental & 193 \\
\hline Ensino Médio & 96 \\
\hline Atendimento Educacional Especializado & 7 \\
\hline Atividades Complementares & 52 \\
\hline Total de Matrículas & 763 \\
\hline
\end{tabular}

Fonte: Paraná (2020b).

Dos 45 professores indígenas em atuação, apenas dois possuem ensino superior cursado em IES privada na modalidade EaD, nos cursos de Pedagogia e Educação Física. Os demais estão cursando ou

\footnotetext{
${ }^{3}$ As atividades complementares referem-se a Treinamento Esportivo; e o Programa Mais Aprendizagem que enfatiza a leitura, interpretação, escrita e resolução de problemas (PARANÁ, 2020).
} 
concluíram o ensino médio e atuam como professores regentes na educação infantil, nas aulas de língua kaingang (da educação infantil ao ensino médio) e, na grande maioria, são auxiliares de professores nãoíndios nas turmas dos anos iniciais do ensino fundamental. Os professores não indígenas que atuam nos anos iniciais, possuem graduação em Pedagogia e os que atuam nos anos finais e ensino médio, possuem graduações nas áreas específicas.

A direção da escola é conduzida por uma professora não indígena, escolhida pela comunidade, e a direção auxiliar, em 2017, foi assumida por uma professora indígena, graduada em Pedagogia. Elas desenvolvem as atividades de gestão em conjunto com a equipe pedagógica, composta por mais três pedagogas não indígenas e tomam decisões em consonância com as deliberações das lideranças indígenas. As funções de serviços gerais e secretaria (Agente Educacional I e II) contemplam funcionários indígenas e não indígenas (PARANÁ, 2020).

Em se tratando de uma escola bilíngue, em consonância com a legislação atual, o ensino deve ocorrer em língua kaingang e portuguesa. Pela história da leitura (SOLÉ, 2003) e da escrita (CAGLIARI, 1995), é sabido que a língua portuguesa possui, há tempos, alfabeto, gramática, dicionários, livros de vários tipos, jornais, revistas, poemas, contos, músicas, parlendas... ou seja, diversos materiais escritos que circulam tanto na escola como em outros ambientes da sociedade expondo os diferentes gêneros textuais. A partir da aquisição do código alfabético, a criança, tendo contato e utilizando estes variados materiais, gradativamente, avança no domínio da escrita e da leitura, ampliando essas habilidades por meio do que tem sido chamado de letramento (STREET, 20I0).

Com a língua kaingang, estudos de Val Floriana (1912), Lima (1842) e Wiesemann, (1978) mostram que quando os indígenas Kaingang foram sendo aldeados e estudados, entre os séculos XIX e $X X$, sua língua oral começou a ser registrada, e atualmente há um sistema de escrita divulgado por Wiesemann $(1978 ; 2002)$ que, por meio de acordos celebrados entre a Fundação Nacional do Índio (FUNAI) e a agência norte americana, Summer Instituto of Linguistcs (BARROS, I994; FAUSTINO, 2006) oportunizou a este instituto o aprimoramento do alfabeto, a elaboração de um vocabulário (dicionário Kaingang), a tradução de parte da Bíblia, produção de hinos evangélicos e publicação de cartilhas de alfabetização. Após esse material de cunho evangelizador que proporcionou a aprendizagem da língua escrita kaingang no Paraná, houve escassas iniciativas para publicação de material bilíngue didático-cientifico.

Observa-se, com base em estudos de Silva (200I) sobre representações visuais Kaingang; em Tommasino (1995, p. 49) que historiciza os mitos revelando "[...] os dois elementos fundamentais da organização social Kaingang: a divisão em metades e as festas", que as "representações visuais" usadas por meio dos grafismos, dos rituais sagrados, da confecção dos balaios, das pinturas corporais, das marcas que representam as metades, Kamé e Kainrú, bem como os cantos e as danças, podem remeter a uma forma de leitura, visto que transmitem uma mensagem. Porém estes conhecimentos próprios Kaingang não 
fazem parte dos currículos escolares no Paraná. Citamos um exemplo, de um velho sábio Kaingang, Sr. Domingos Crispim, registrado em cadernos de campo do Observatório da Educação Escolar Indígena/LAEE-UEM ao dizer que,

[...] quando saía para caçar, em dois ou três jamré (parente/cunhado), cada um seguia para um lado, e, caso se deparasse, no caminho, com uma forquilha com um chumaço de pelo de ójoro (Anta) cravado ao meio, significava que um já tinha caçado o animal e estava convidando os demais para jantarem na casa dele" (CRISPIM, apud, MENEZES, p. 138, 2016).

Por meio do uso de uma "forquilha e um chumaço de pelo" de um dos animais mais importantes na alimentação tradicional Kaingang, esta sociedade demonstra ter criado complexos códigos de comunicação que ainda não foram devidamente estudados e, portanto, não problematizam as costumeiras formas de se ensinar e aprender nas escolas em contextos indígenas.

\section{LEITURA E ESCRITA NO CONTEXTO DA ESCOLA INDÍGENA}

No espaço escolar o ensino das habilidades de ler e escrever ocorrem de forma sistemática e planejada, nesse sentido as representações produzidas pelos Kaingang no decorrer da história, precisam ser melhor contempladas na organização do currículo e do planejamento didático pedagógico, uma vez que uma criança antes de ingressar na escola, como afirma Luria (200 I, p. I43) "[...] já adquiriu um patrimônio de habilidades e destrezas que a habilitará a aprender a escrever em um tempo relativamente curto".

Ainda que as crianças na escola desta comunidade aprendam o código da língua escrita em curto período de tempo, podendo ler com autonomia, em português, um texto completo de livro didático quando está entre $\circ 3^{\circ}$ e $4^{\circ}$ ano do ensino fundamental, observa-se pouca presença da escrita e de materiais de leitura em kaingang no ambiente escolar e comunitário. Mesmo sendo o português a língua definida pela comunidade para a alfabetização, cartazes, informações, convites de eventos, listas de compras e outros materiais presentes no cotidiano da escola poderiam estar escritos em kaingang para dar maior visibilidade e prestígio à língua materna da comunidade e instigar as crianças a terem maior contato com sua língua, na forma escrita.

Da forma como está organizado, o ensino da língua portuguesa predomina nas escritas da escola indígena, como pode ser verificado no projeto pedagógico, nos planejamentos, calendários, atividades e outros. Apenas os planejamentos dos professores indígenas são feitos em kaingang e, ainda assim, em forma de tradução, o que, pouco estimula a criatividade, a autonomia e os saberes dos professores indígenas.

$\mathrm{Na}$ escola, em 2016, havia três turmas de primeiro ano com 68 alunos matriculados com idade entre cinco a sete anos. Durante o período de observação em duas turmas de primeiro ano, verificamos 
que os encaminhamentos dados pelas professoras não indígenas, que são as regentes das turmas, conduzem para a aquisição do código alfabético em língua portuguesa. Nas salas havia uma professora auxiliar indígena, que traduzia ao kaingang as explicações da professora não indígena, sendo a explicação oral em kaingang e as atividades escritas em língua portuguesa.

Observou-se uma rotina estabelecida pelas professoras dos primeiros anos. Antes de iniciar a aula, faziam uma oração, na sequência as crianças recebiam um lanche (bolacha, ou uma barrinha de cereal), e após, iniciava-se a atividade de leitura do alfabeto, das vogais, dos números e das regras de convivência. Para a realização dessa leitura, a professora mostrava a letra, identificava-a e solicitava que as crianças repetissem. Da mesma forma procedia com as vogais, os números e as regras escritas. Após a leitura, a professora entregava às crianças uma pasta com o caderno, lápis, borracha e lápis de cor solicitando que fizessem o registro da pauta presente no quadro de giz, colocassem a data e iniciassem as atividades de escrita.

A leitura em situações dessa forma, explica Solé (1998, p. 23), é um "modelo ascendente - buttom up", isto quer dizer, que, "[...] o leitor perante o texto, processa seus elementos componentes, começando pelas letras, continuando com as palavras, frases... em um processo ascendente, sequencial e hierárquico que leva à compreensão do texto".

Esta metodologia está baseada no método sintético usado com os indígenas desde o período da catequização (MENEZES, 2016), partindo de unidades menores, as letras, até chegar a frases e textos. A escrita torna-se uma ação de repetição e cópia do quadro. As cópias são seguidas de atividades de "ligar", "completar", "cobrir", "caçar-palavras" por meio da entrega de reproduções em papel sulfite, atividades essas, cujos modelos são, na maioria das vezes, retirados da internet. No período observado, não havia um livro didático para as crianças.

Amaral (201 I , p. 29) explica que se "[...] existe uma consistência linguística na preservação da língua indígena" e as crianças começam a estudar em língua portuguesa "[...] têm que priorizar práticas que favoreçam a aquisição". Há uma política educacional intercultural e bilíngue, porém não há programas governamentais seguros e bem desenvolvidos de alfabetização em línguas indígenas no Brasil. Não há materiais diversificados e apropriados para o ensino da leitura e escrita em kaingang, é baixíssimo o percentual de professores indígenas formados atuando nas escolas indígenas, as equipes pedagógicas são compostas majoritariamente por professores não índios, não há gramáticas e linguistas Kaingang no Paraná; desta forma a comunidade da Terra Indígena Ivaí tem optado pela alfabetização em língua portuguesa e definem que o ensino da língua kaingang, escrita, deve ocorrer a partir do terceiro ano do ensino fundamental, quando as crianças já tiverem se apropriado da leitura e escrita em língua portuguesa.

Entretanto é importante refletir sobre a metodologia e o conteúdo adotados no ensino da língua portuguesa em uma escola indígena. As atividades desenvolvidas levam as crianças a memorizarem o 
alfabeto e a partir dele escrever palavras, aproximando-se do método sintético de alfabetização (FRADE, 2007). Este método dispõe de uma sequência lógica, de muitas cartilhas e foi muito utilizado no Brasil, em escolas públicas, até meados dos anos de 1970. Embora eficiente do ponto de vista técnico, trata-se de um ensino de leitura e escrita descontextualizado, prevalecendo a memorização de códigos sonoros e visuais - fonemas e grafemas - e a reprodução da escrita, promovendo uma aprendizagem mecânica, desvinculada da função social da escrita.

método sintético, muito conhecido e utilizado no Brasil por décadas, já foi questionado por inúmeros estudiosos e outras metodologias de ensino da leitura e escrita já foram amplamente desenvolvidas e divulgadas. Conforme Menezes (2016) para que uma metodologia de ensino da leitura e escrita seja adequada à realidade dos estudantes e se torne significativa sua aprendizagem, há a necessidade da adoção de uma concepção de ensino e aprendizagem que compreenda ser a escrita uma linguagem como muitas outras. Nesta concepção a Teoria Histórico-Cultural (VIGOTSKI, I983, 2007) pode contribuir com a ação do professor neste direcionamento.

O ensino da língua kaingang em sua forma escrita inicia-se no terceiro ano nesta escola. Quem ministra são professores indígenas, com formação em nível médio. A metodologia usada nas aulas é semelhante à usada pelos professores não indígenas durante a alfabetização da língua portuguesa, ou seja, o método sintético. Os professores indígenas seguem planejamentos escolares semelhantes e passam no quadro palavras e sílabas em kaingang para os/as alunos/as copiarem no caderno pedindo que escrevam palavras e, na sequência, aplicam atividades fotocopiadas. Em algumas situações realizam atividades de pintura e exercícios de ligar palavras a desenhos e completar sílabas faltantes nas palavras.

Amaral (2011, p. 29), afirma ser necessário "[...] adotar estratégias pedagógicas diferenciadas", havendo situações onde "a língua indígena pode ser trabalhada com atividades de letramento". Ou seja, se a criança possui o domínio da língua em sua forma oral, já possui o domínio de um código escrito (em português), após aprender as diferenças dos alfabetos, observar as diferenças dos fonemas/grafemas das duas línguas, compete ao professor desenvolver metodologias que incorporem a leitura e escrita dessa língua e para isso a importância do uso dos gêneros textuais escritos em língua kaingang.

Os textos podem ser escritos em cartazes, com uso de imagens, símbolos, narrativas contadas pelos mais velhos, receitas de alimentos tradicionais, como por exemplo, a receita do Ẽmi (bolo azedo); listas de nomes de animais que vivem na aldeia, listas de nomes próprios kaingang e outros materiais que podem ser produzidos e trabalhados pelos professores indígenas objetivando dar significado no processo de ensino e melhor evidenciar a função da linguagem escrita.

De acordo com esse encaminhamento, propusemos, no âmbito da Ação Saberes Indígenas na Escola, em 2017, uma formação específica com professores indígenas dessa escola, cujo objetivo foi incentivar entre eles o estudo sobre metodologias mais contextualizadas, para o ensino da leitura e da 
escrita em língua kaingang, dando maior visibilidade aos elementos e oportunizando a produção de materiais escritos/ilustrados.

Propusemos estudos teórico-práticos sobre a organização do planejamento docente, uma vez que a metodologia faz parte do planejamento. Participaram da formação, no período, professores indígenas, uma pedagoga e a direção da escola, totalizando 22 pessoas. Os professores e professoras indígenas tinha em torno 22 a 24 anos, em sua maioria, e nenhum deles tinha curso superior.

Houve discussões sobre possibilidades de ensino da leitura e escrita, contemplando elementos da cultura Kaingang e colocando atenção aos planejamentos e sua execução pois,

$\underline{\text { Primeiro, o professor precisa conhecer e definir uma concepção teórico-metodológica. Segundo, }}$ definir o que pretende que o aluno aprenda e para que ele precisa aprender, ou seja, definir os objetivos. Terceiro, promover a aprendizagem de forma significativa para todos; isso envolve pensar nas ações docentes e discentes que estarão em consonância com a concepção teóricometodológica adotada (MENEZES, 20 I2, p. 126).

Após discussão e pesquisas em materiais disponibilizados, optamos por trabalhar com os professores a partir dos gêneros textuais, ressaltando a importância que Amaral (20 I I) e Street (20 I0), pontuam sobre o letramento, e também, com a intenção de trazer elementos da cultura Kaingang para uma atividade concreta de uso da leitura e escrita. A formação objetivou a visibilidade da língua kaingang com elementos culturais, nesse sentido, os professores indígenas optaram pela produção de cartazes, pois esse gênero textual contribui com a visibilidade da leitura e escrita, por serem materiais "compostos por imagem e texto, que tem por objetivo informar e instruir o leitor sobre um determinado assunto que diz respeito a uma coletividade" (FERREIRA; VIEIRA, 2013, p. 102). Os planejamentos organizados e as práticas desenvolvidas com os professores, poderiam, posteriormente ser feitos com as crianças a partir do primeiro ano do ensino fundamental.

Seguimos a orientação de Ferreira e Vieira (20I3) em relação a sequência para o trabalho com esse gênero textual, cartazes e, a partir de leituras e exposições, os professores identificaram os elementos que os compõe: título; imagens; conteúdo; estilo da produção e fontes. Discutiu-se, o objetivo desse tipo de material e em que lugares são encontrados/utilizados e quais suas finalidades.

Foram pesquisadas e selecionadas várias imagens que retratavam temas como: alimentação Kaingang; moradia; artesanato; artefatos, plantas e animais. Os professores indígenas organizaram-se em grupos e decidiram qual/quais tema/s trabalhariam na confecção dos cartazes, definiram como seria o estilo da produção (letras, cores, grafismos, disposição das imagens e textos escritos). Os textos dos cartazes tratando dos temas elencados foram escritos em língua kaingang e houve um acalorado debate entre eles sobre as escritas, as escolhas das palavras, a construção das frases, mobilizando muitos a irem ao quadro de giz, testar palavras, receber a contribuição dos parentes e produzir diferentes enunciados. 
O uso de gêneros textuais, como o caso descrito aqui, incluindo temas que fazem parte da cultura Kaingang, permite dar maior significado às práticas pedagógicas, maior visibilidade à língua kaingang na escola e estimular o debate entre professores de uma mesma Terra Indígena (mesmo dialeto), a irem criando consensos sobre suas escritas, uma vez que não existem gramáticas da língua Kaingang o que gera certa insegurança aos professores iniciantes, na escrita de sua língua, somada a ausência de formação acadêmica.

\section{CONCLUSÃO}

Muitos são os temas de ampla discussão na área da educação, dentre os quais enfatizamos nesse texto o do ensino da leitura e da escrita, fundamental para todos os níveis educacionais e desenvolvimento do processo de ensino e aprendizagem contextualizados. Na modalidade da educação escolar indígena, essa e outras temáticas são tratadas de forma interdisciplinar, sobretudo a partir dos anos de 1970 e de um redimensionamento das pesquisas e movimentos no Brasil.

Houve no período, o fortalecimento dos movimentos indígenas e suas organizações próprias que pautaram mudanças na educação, em um contexto favorável de abertura para políticas da diversidade cultural no âmbito do neoliberalismo e da reforma do Estado da década de 1990 (FAUSTINO, 2006). Foram consideráveis as conquistas da Constituição de 1988 com o direito, aos indígenas, da utilização de suas línguas maternas no ensino fundamental, bem como a processos próprios de aprendizagem (BRASIL, 1988), impulsionando mudanças nas leis e promovendo a construção de uma política de interculturalidade e bilinguismo para as escolas indígenas.

O ensino bilíngue sendo um direito dos povos indígenas no Brasil e regulamentado pelas legislações infraconstitucionais levou escolas indígenas a repensar suas ações educativas. A partir da legislação e da organização sociolinguística da Terra Indígena Ivaí, entendemos que o corpo docente da escola professores índios e não índios - assim como a equipe de gestão, possuem fundamental importância no ensino da leitura e escrita de crianças em processo de alfabetização bilíngue.

Para que esse ensino esteja em consonância com os fundamentos de uma escola indígena intercultural, específica, bilíngue e diferenciada, há a necessidade de formação permanente dos professores, bem como condições dos professores de fazerem pesquisas, conversarem com os sábios e sábias da comunidade e estudarem sobre bilinguismo, alfabetização e letramento, visando a uma produção contextualizada de materiais didáticos.

O texto evidenciou, a partir de estudos e pesquisas realizados de cunho etnográfico e documental em uma Terra Indígena no Vale do Ivaí, no Paraná, que o ensino da língua portuguesa é uma opção comunitária que faz parte das estratégias dos Kaingang para se relacionarem com a comunidade envolvente 
e com o poder público. Dessa forma, há uma grande complexidade no ensino, visto que as crianças são falantes da língua indígena e alfabetizadas em língua portuguesa.

Alguns elementos da educação e da interação das crianças Kaingang com os adultos são discutidos. O lugar que a criança ocupa nas sociedades tradicionais mostra que não é possível a aplicação da mesma lógica de educação escolar ocidental, visto que a construção da autonomia é fundamental nas sociedades Kaingang. As crianças aprendem pela observação, pela vivência, pelas narrativas dos mais velhos e pelas atividades práticas; com mínimos comandos verbais dos adultos.

Tendo a comunidade optado pelo envio de suas crianças à escola, é relevante que esta instituição, além do diálogo permanente que estabelece com as lideranças, procure conhecer processos próprios de aprendizagem da criança Kaingang e da organização das famílias extensas, observando e inventariando algumas de suas particularidades e colocando-as em diálogo com os conteúdos escolares. É relevante, também, que os professores indígenas, mesmo sem formação acadêmica sejam mais estimulados pela equipe pedagógica a ocuparem maiores espaços de atuação pedagógica na escola, ainda que os espaços que os professores indígenas ocupam, nesta comunidade, sejam definidos pelas regras da política nativa, conduzida pelas lideranças.

O texto levanta, ainda, outra questão fundamental, sem a qual não é possível um ensino adequado da leitura e escrita: a investigação sobre o conhecimento sociolinguístico dos estudantes. Neste sentido, o texto procurou refletir sobre o fato da comunidade ser falante da língua kaingang, como primeira língua, ter um profundo conhecimento oral da mesma, as crianças se comunicam nessa língua em todos os espaços e, na escola, e serem alfabetizadas em língua portuguesa.

Entender a língua portuguesa, por volta dos oito ou nove anos não implica que a criança faça uso desta língua ou que a incorpore em suas ações cotidianas, sendo esta apenas utilizada em sala de aula, com professores não-indígenas e para ler e escrever conteúdos escolares. Porém, devemos nos perguntar qual o sentido das leituras e escritas que fazem na escola? Isto poderia ser mais bem debatido com a comunidade escolar, mas, para tanto, os professores necessitam ter, em suas cargas horárias, espaços adequados para a pesquisa e o diálogo permanente com a comunidade.

Observou-se que, mesmo aprendendo a ler e escrever em português na escola indígena, isso proporciona às crianças Kaingang a ampliação de suas competências bilíngues, o que é necessário tendo em vista a realidade vivida pelos povos indígenas na atualidade. Carecemos, no entanto, de estudos que evidenciem o impacto da prática da alfabetização em língua portuguesa, no uso da língua kaingang em sua forma oral nesta comunidade.

Com relação aos professores, evidencia-se a necessidade de cumprimento, por parte do estado, de uma formação adequada e baseada na legislação específica da área, bem como a melhor formação de 
professores indígenas no ensino superior (GEHRKE; SAPELLI; FAUSTINO, 2019) para que possam fortalecer e efetivar a escola intercultural e bilíngue em suas comunidades.

De forma geral, no Paraná, as escolas indígenas carecem de oferta e diversificação de materiais didáticos específicos, currículos e projetos bilíngues, cuja produção/construção tem relação com a maior formação e atuação dos professores indígenas e a melhoria de sua situação de trabalho que, sendo por contratos temporários, não Ihes estimula a consolidar uma carreira docente permeada por pesquisas e produções didático-cientificas.

Concluímos problematizando a necessidade de maiores estudos e pesquisas interdisciplinares sobre o tema da alfabetização indígena, contando com a participação de intelectuais e professores indígenas, dos sábios indígenas, das lideranças, das famílias e dos professores não indígenas que atuam nas escolas indígenas buscando, assim, fortalecer os conhecimentos culturais na escola e a língua indígena, bem como os processos próprios de aprendizagem Kaingang.

\section{REFERÊNCIAS}

AMARAL, Luiz. Bilinguismo, aquisição, letramento e o ensino de múltiplas línguas em escolas indígenas no Brasil. In: JANUÁRIO, Elias; SILVA, Fernando Selleri. Cadernos de educação escolar indígena, Faculdade Indígena Intercultural. Cáceres: Editora da UNEMAT, v.9, n. I , p. I3-32, 201 I.

ANDRIOLI, Luciana Regina. A política de educação infantil indígena e a sustentabilidade das famílias kaingang: aprendizagens nas aldeias e nas cidades, 2019. 275 f. Tese (Doutorado) - Programa de PósGraduação em Educação, Universidade Estadual de Maringá, Maringá, 2019.

ANDRIOLI, Luciana Regina. FAUSTINO, Rosangela Celia. Vivências de crianças indígenas Kaingang na cidade: elementos para a aprendizagem e o desenvolvimento. Revista Humanidades e Inovação, Palmas, Tocantins, Vol. 6, n. I5, p. 54-69, 2019.

BANDEIRA, Toni Juliano. Aspectos da língua Kaingang. Travessias, Cascavel, vol. 8, p. 377-402, 2014. Disponível em: http://e-revista.unioeste.br/index.php/travessias/article/view/I0655/8 I I0. Acesso: I3 abr. 2020.

BARROS, Maria Cândida Drumond Mendes. Educação bilíngue, linguística e missionários. Em Aberto, Brasília, DF, ano 14, n. 63, p. 18-37, jul./set. 1994.

BORBA, Telemaco. Actualidade Indígena. Coritiba, Impressora Paranaense. 1908.

BRASIL. Constituição (1988). Constituição da República Federativa do Brasil. 23. Ed. Brasília, DF: Senado, 1988.

BRASIL. Decreto n 6.86I de 2009. Dispõe sobre a Educação Escolar Indígena, define sua organização em territórios etnoeducacionais e dá outras providências. Brasília, 2009. Disponível em: http://www.planalto.gov.br/ccivil 03/ Ato2007-2010/2009/Decreto/D6861.htm. Acesso em: 20 mar. 2020. 
BRASIL. Ministério da Educação. Parecer n 14 de setembro de 1999. Brasília, 1999. Disponível em:

BRASIL. Ministério da Educação. Referenciais para a formação de professores indígenas. Secretaria de Educação Fundamental. Braślia: MEC; SEF, 200I.

BRASIL. Portaria Interministerial n 559 de 16 de abril de 1991. Sobre a Educação Escolar para as Populações Indígena. Brasilia, 1991. Disponível em: https://cimi.org.br/2004/06/21816/. Acesso em: 20 mar. 2020.

BRASIL. Referencial curricular nacional para as escolas indígenas. Ministério da Educação e do Desporto. Secretaria de Educação Fundamental. Brasília: MEC/SEF, 1998.

BRASIL. Resolução $n^{\circ}$ I de 7 de janeiro de 20I5. Institui Diretrizes Curriculares Nacionais para a Formação de Professores Indígenas em cursos de Educação Superior e de Ensino Médio e dá outras providências. Brasília, 2014. Disponível em:

http://portal.mec.gov.br/index.php?option =com docman\&view $=$ download\&alias $=16870$-res-cne-cp001-070 I 201 5\&ltemid=30192. Acesso em: 20 mar. 2020.

BRASIL. Resolução n 5 de 22 de junho de 2012. Define Diretrizes Curriculares Nacionais para a Educação Escolar Indígena na Educação Básica. Brasília, 2012. Disponível em: http://www.crmariocovas.sp.gov.br/Downloads/ccs/concurso_2013/PDFs/resol federal 05 12.pdf. Acesso em: 20 mar. 2020.

BRITO, Percival Leme. Em terra de surdos-mudos. In: GERALDI, J.W. O texto na sala de aula: leitura e produção. Cascavel: ASSOESTE, 1990.

CAGLIARI, Luiz Carlos. Alfabetização e lingüística. São Paulo: Scipione, 1995.

CLAUDINO, Zaqueu Key. As narrativas kaingang nas aldeias. In: Claudino FAGUNDES, Luiz Fernando Caldas; FARIAS, João Mauricio. Objetos-sujeitos: a arte kaingang como materialização de relações. Porto Alegre: Editora Deriva: FUNAI, 20 I I. p. 3 I-38.

COROAIA, Maria Elenir Neves. Reflexões sobre as práticas kaingang de cuidados com a gestação, parto e pós-parto e suas interfaces com o sistema oficial de saúde. 2013. 104 f. Dissertação (Mestrado) Mestrado Profissional em Desenvolvimento Sustentável, Universidade de Brasília, Brasília 2013.

FAUSTINO, Rosangela Celia; MOTA, Lucio Tadeu. Crianças indígenas: o papel dos jogos, das brincadeiras e da imitação na aprendizagem e no desenvolvimento. Acta Scientiarum, Maringá, vol. 38, n. 4, p. 395-404, Oct-Dec., 2016.

FAUSTINO, Rosangela Celia; NOVAK, Maria Simone Jacomini; RODRIGUES, Isabel Cristina. O acesso de mulheres indígenas à universidade: trajetórias de lutas, estudos e conquistas. Tempo e Argumento. Florianópolis, v. I2, n. 29, 2020

FAUSTINO. Rosangela Celia. Política educacional nos anos de 1990: o multiculturalismo e a interculturalidade na educação escolar indígena, 2006. 329 f. Tese (Doutorado) - Programa de PósGraduação em Educação, Universidade Federal de Santa Catarina, Florianópolis, 2006.

FERNANDES, Ricardo Cid. Política e parentesco entre os Kaingang: uma análise etnológica. 2003. 288 f. Tese (Doutorado) - Universidade de São Paulo, São Paulo, 2003. 
FERREIRA, Bruno. Educação Kaingang: processos próprios de aprendizagem e educação escolar, 20 I 4. 99 f. Dissertação (Mestrado) - Universidade Federal do Rio Grande do Sul, Faculdade de Educação, Programa de Pós-Graduação em Educação, Porto Alegre, 2014.

FERREIRA, Helena Maria; VIEIRA, Mauricéia Silva de Paula. Gêneros textuais e discursivos: guia de estudos. Lavras: UFLA, 2013.

FRADE, Isabel Cristina Alves da Silva. Métodos de alfabetização, métodos de ensino e conteúdos da alfabetização: perspectivas históricas e desafios atuais. Revista Educação, Santa Maria, v. 32. n. I . p. 2 I 39. 2007. Disponível em: https://periodicos.ufsm.br/reveducacao/article/view/658. Acesso em: 10 abr. 2020.

GARLET, Marinez. Entre cestos e colares, faróis e parabrisas: crianças Kaingang em meio urbano, 2010. 269 f. Dissertação (Mestrado) - Programa de Pós-Graduação em Serviço Social, Pontifícia Universidade Católica do Rio Grande do Sul, Porto Alegre, 2010.

GEHRKE, Marcos; SAPELLI, Marlene Lucia, Siebert; FAUSTINO, Rosangela Celia. A formação de pedagogos indígenas em alternância no Paraná: uma contribuição à interculturalidade e ao bilinguismo.

Revista Brasileira de Educação do Campo. Tocantins, v.4, 2019.

HORTA BARBOZA, Luiz Bueno. A pacificação dos gaingans paulistas: hábitos, costumes e instituições desses índios. Rio de Janeiro, RJ: Jornal do Commercio, 1913.

http://portal.mec.gov.br/docman/marco-20 I 2-pdf/l0204- I3-parecer-cne-ceb- I 4-99-diretrizescurriculares-nacionais-da-educacao-escolar-indigena/file. Acesso em: 20 mar. 2020.

IBGE. Instituto Brasileiro de Geografia e Estatística. Censo Demográfico 20 I0: características gerais dos indígenas: resultados do universo. Rio de Janeiro: IBGE, 2010.

IBGE. Os indígenas no Censo Demográfico 20 I0: primeiras considerações no quesito cor ou raça. Rio de Janeiro: IBGE/MPOG, 20I2. Disponível em:

https://indigenas.ibge.gov.br/images/indigenas/estudos/indigena_censo20 I0.pdf. Acesso em: 10 mar. 2020.

ISA. Instituto Socioambiental. Terras Indígenas no Brasil. Ivaí, 2013. Disponível em: https://terrasindigenas.org.br/pt-br/pesquisa/povo//27. Acesso em: 30 mar. 2020.

LIMA, Francisco das Chagas. Memória sobre o descobrimento e colônia de Guarapuava. Revista Trimensal de Historia e Geographia ou Jornal do Instituto Historico e Geographico Brasileiro. Rio de Janeiro: Typographia de João Ignacio da Silva. Tomo IV, n. 13, p. 43-64, 1842.

LURIA, Alexander R. O desenvolvimento da escrita na criança. In: LEONTIEV, Alexis; VYGOTSKY, Lev. S.; LURIA, Alexander Romanovich. Linguagem, desenvolvimento e aprendizagem. São Paulo: Ícone, 2001 .

MABILDE, Pierre François Alphonse Booth. Apontamentos sobre os indígenas selvagens da nação coroados dos matos da província do Rio Grande do Sul: | 836- | 866. São Paulo: IBRAS. Brasília: INL, Fundação Nacional Pró-Memória, 1983.

MENEZES, Maria Christine Berdusco. A política de educação escolar indígena e o processo de alfabetização em uma comunidade Kaingang no Paraná. 2016. 244 f. Tese (Doutorado)-Programa de Pós-Graduação em Educação, Universidade Estadual de Maringá, Maringá, 2016. 
MENEZES, Maria Christine Berdusco. Diversidade cultural, práticas pedagógicas e educação escolar. In: CARVALHO, Elma júlia G.de; FAUSTINO, Rosângela Célia. (Orgs.). Diversidade Cultural: políticas e práticas educacionais. Maringá: Eduem, 2012, p. 117-133.

MOTA, Lucio Tadeu. As guerras dos índios Kaingang: a história épica dos índios Kaingang no Paraná: 1760- 1924. Maringá: Eduem, 1994.

NASCIMENTO, Marcia. Tempo, modo, aspecto e evidencialidade em Kaingang, 20I3. I40 f. Dissertação (Mestrado) - Programa de Pós-Graduação em Linguística, Universidade Federal do Rio De Janeiro, 2013.

NOVAK, Maria Simone Jacomini. Os Organismos internacionais, a educação superior para indígenas nos anos de 1990 e a experiência do Paraná: estudo das ações da Universidade Estadual de Maringá. 2014. 342 f. Tese (Doutorado)-Programa de Pós-graduação em Educação, Universidade Estadual de Maringá, Maringá, 2014.

PARADISE, Ruth. Estilo interacional e o significado não verbal: crianças Mazahua aprendem como viver no modo separado-mas-junto. Práxis Educativa. Ponta Grossa, vol. 7, Número Especial, p. I I-30, dez. 2012.

PARANÁ, Dia a dia da educação. Consulta escolas, 2020a. Disponível em: http://www.consultaescolas.pr.gov.br/consultaescolas-java/pages/templates/initial2.jsf?windowld=ac4. Acesso em: 26 mai. 2019.

PARANÁ. Dia a dia da educação. Consulta escolas. Escola Gregório Kaekchot, CEl Cacique-EFM, 2020b. Disponível em: http://www.consultaescolas.pr.gov.br/consultaescolasjava/pages/paginas/ensinoEscola/consultasEnsino.jsf?windowld=d3e. Acesso em: 30 mar. 2020.

PARANÁ. Projeto multissetorial para o desenvolvimento do Paraná: estratégia de participação dos povos indígenas (EPPI). Curitiba: SEPL, SEAB, SEED, SESA, 2016.

PARANÁ. Secretaria de Estado da Educação. Superintendência da Educação. Departamento da Diversidade. Ler, escrever e ser Kaingang no Paraná. Curitiba: SEED-PR, 2010.

PARANÁ. Secretaria de Estado da Educação. Superintendência da Educação. Departamento da Diversidade. Kanhgág Jykre. Curitiba: SEED-PR, 20। I.

PINHEIRO, Valdemir. Infância Kaingang na Terra Indígena Xapecó-SC: saber e aprender. 20 I5. 43 f. Trabalho de Conclusão de Curso. (Licenciatura Intercultural Indígena do Sul da Mata Atlântica) - Universidade Federal de Santa Catarina, Florianópolis, 2015.

RODRIGUES, Aryon Dall'Igna. Flexão relacional no tronco linguístico Macro-Jê. Revista Brasileira de Linguística Antropológica, Brasília, DF, vol. 4, n. 2, p. 267-277, 2012.

SILVA, Sergio Baptista da. Etnoarqueologia dos grafismos Kaingang: um modelo para a compreensão das sociedades Proto-Jê meridionais. 200 I. 367 f. Tese (Doutorado)-Programa de Pós-Graduação em Antropologia Social, Faculdade de Filosofia, Letras e Ciências Humanas, São Paulo, São Paulo, 200 I.

SILVA, Thais Regina Mantovanelli da. Crianças invisíveis da reserva indígena Icatu/SP. 20 I I . I4 I f. Mestrado (Dissertação) - Programa de Pós-Graduação em Antropologia Social, Universidade Federal de São Carlos, São Carlos, 2011. 
SILVEIRA, Déa Maria Ferreira (Org.) Kanhgág si kãme. Guarapuava: Conselho Indígena Regional de Guarapuava, 1993.

SOLÉ, Isabel. Estratégias de leitura. Porto Alegre: ArtMed, 1998.

SOLÉ, Isabel. Ler, leitura, compreensão: "sempre falamos da mesma coisa?". In: TEBEROSKY, Ana et al.

Compreensão de leitura: a língua como procedimento. Porto Alegre: ArtMed, 2003.

STREET, Brian V. Os novos estudos sobre o letramento: histórico e perspectivas. In: MARINHO, Marildes; CARVALHO, Gilcinei Teodoro. (Orgs.). Cultura escrita e letramento. Belo Horizonte, MG: UFMG, 2010.

TOMMASINO, Kimiye. A história dos Kaingáng da Bacia do Tibagi: uma sociedade Jê Meridional em movimento, 1995. 35 I f. Tese (Doutorado) - Departamento de Antropologia. Faculdade de Filosofia, Letras e Ciências Humanas, São Paulo, São Paulo, 1995.

VAL FLORIANA, Mansueto Barcatta de. Diccionarios. Kainjgang-Portuguez e Portuguez- Kainjgang. Revista do Museu Paulista. Ordem dos missionários capuchinhos do Estado de São Paulo. Tomo XII, São Paulo, 1912.

VEIGA, Juracilda. Organização social e cosmovisão Kaingang: uma introdução ao parentesco, casamento e nominação em uma sociedade Jê Meridional. 1994. 226f. Dissertação (Mestrado) - Programa de PósGraduação em Antropologia Social, Universidade Estadual de Campinas, Campinas, 1994.

VIGOTSKI, Lev Semenovich. A formação social da mente: o desenvolvimento dos processos psicológicos superiores. 7. ed. São Paulo: Martins Fontes, 2007.

VYGOTSKI, Lev Semiónovich. Obras escogidas. Obras Escogidas III: problemas del desarrollo de la psique. Madrid: Editorial Pedagógica, 1983.

WIESEMANN, Ursula Gojtéj. Dicionário. Kaingang-Português. Português-Kaingang. Curitiba. Editorial Evangélica Esperança, 2002.

WIESEMANN, Ursula Gojtéj. Os dialetos da língua Kaingang e Xokleng. Contribuições do Summer Institute of Linguistics. Rio de Janeiro, 1978.

\section{COMO CITAR ESSE ARTIGO}

\section{Associação Brasileira de Normas Técnicas (ABNT)}

MENEZES, Maria Christine Berdusco; FAUSTINO, Rosângela Célia; NOVAK, Maria Simone Jacomini. O ensino da leitura e escrita em uma escola indígena Kaingang: contribuições ao bilinguismo. Debates em Educação, Maceió, v. 12, p. 275-296, set. 2020. ISSN 2175-6600. Disponível em: https://www.seer.ufal.br/index.php/debateseducacao/article/view/l 0020. Acesso em: dd mmm. aaaa.

\section{American Psychological Association (APA)}

Menezes, M., Faustino, R., \& Novak, M. (2020). O ensino da leitura e escrita em uma escola indígena Kaingang: contribuições ao bilinguismo. Debates em Educação, 12(Esp), 275-296. doi: https://doi.org/10.28998/2175-6600.2020v12nEspp275-296 